\title{
Study on Alloy Steel TEW 6582 Machined Surface Rougness Under Dry Machining
}

\author{
Suhardi Napid ${ }^{1}$, Muhammad Rafiq Yanhar ${ }^{1}$, Ahmad Bakhori ${ }^{1}$, Abdurrozzaq Hasibuan ${ }^{2}$, Oris Krianto Sulaiman ${ }^{2}$, \\ Mhd. Asaad ${ }^{3}$ \\ ${ }^{1}$ Faculty of Engineering, Universitas Islam Sumatera Utara, Medan, Indonesia \\ ${ }^{2}$ Faculty of Engineering, Universitas Islam Sumatera Utara, Medan, Indonesia \\ ${ }^{3}$ Faculty of Agriculture, Universitas Islam Sumatera Utara, Medan, Indonesia \\ *Corresponding author E-mail: suhardi.napid@uisu.ac.id
}

\begin{abstract}
The purpose of research is to study the surface roughness of machining results obtained to give consideration that the possibility of dry machining can be realized at alloy steel machining of TEW 6582. In the field of surface texture only discuss the machined surface roughness with some testing that is processing and data analysis can be done statistically. The TEW 6582 alloy steel samples were produced from dry machining operations with 9 cutting forms using standard L $9\left(3^{4}\right)$. In this case 3 variations of tool wear are determined by tool edge wear $(\mathrm{VB})=0.1 \mathrm{~mm}, 0.3 \mathrm{~mm}$ and $0.6 \mathrm{~mm}$ including also in wet machining. To cut the work piece used CNC machine, optical microscope and surface test. The roughness test was obtained the roughness value with dry machining for optimum cutting conditions ie HPK1.0.1 $=1,467 \mu \mathrm{m}, \mathrm{HPK} 8,0.3=2,133 \mu \mathrm{m}$ and HPK8,0.6 $=2,8 \mu \mathrm{m}$ whereas value in wet machining was found with HPB1,0.1 = $1,581 \mu \mathrm{m}, \mathrm{HPB} 8.0 .3=2,304 \mu \mathrm{m}$ and HPB8,0.6 = 2,906 $\mu \mathrm{m}$. From the above machining results data, HPK8.06 can be determined as the most optimum cutting condition which can be concluded that dry machining gives better machining results roughness through Ravg value and no significant difference is obtained when compared to wet machining after statistically analyzed, so that dry machining is a good chance that can be realized in manufacturing and automotive industries.
\end{abstract}

Keywords: Dry machining, VB edge wear, surface roughness, alloy steel of T EW 6582

\section{Introduction}

Surface roughness is a part of learning about surface integrity (surface integrity). [1], [2]states that surface textures include roughness, lay, waviness and defect. The most common variable modified in the lathe process is the set up parameter of the machine. Cutting speed, feed rate and cutting depth are known by cutting conditions that have a very important impact on surface quality [3].Until now wet machining in industry is still used to cut metal steel [4], [5]reported that 16 percent of the 100 percent of the total production cost is a contribution to the cutting fluid that must be removed. When the 16 percent cost is converted to the total production cost of the automotive industry in America, Germany, Japan reached tens of billions of dollars [6]. The impact of using cutting fluids on wet machining is not only a matter of cost but also to health and the environment. Due to the impact of this cutting fluid, machining experts have been able to provide solutions by recommending green machining [7]. Dry machining is better than wet machining when the carbide tool coated TIN cutting tool steel metals [8]. Cutting fluids, depth of cut, feeding, nose radius affect surface integrity [9]With dry machining on the metal cutting process can increase friction between the tool and the work piece followed by high cutting temperatures so that can to affect the structure of the workpiece, tool wear and BUE [10] Dry machining should be done at high cutting speeds with a special carbide tool layer and has high stiffness properties, able to withstand high temperatures in order to overcome the wear rate of tools [11]. If dry machining is performed on TEW 6582 alloy steel, the possibilities are:

1. High friction and heat in dry machining due to metal cutting with alloy steels having ductile material properties.

2. With the material properties of ductile obtained by continuous chip. Reduction of cutting speed of the possibility adhere chips will occur on surface of the workpiece.

3. The surface hardness of machining results will higher in dry machining compared with wet machining.

The more smooth the surface of the machining results so the better mechanical properties. Due to the negative impact on wet machining is quite large, the dry machining benefit of the cost factor is no sales of chip cleaners, no coolant, no coolant pump, no filter [12]. The above problem can be solved by changing the wet machining method to dry machining method with consequence can reduce production cost and avoid environmental pollution.

\section{Research Purposes}

To review surface roughness of machining results obtained by dry machining method in order to provide a consideration that the possibility of dry machining to be realized in TEW 6582 alloy machining. 


\section{Material and Method}

Table 1: Chemical Composition and Mechanical Properties of Carbide Tool many layers

\begin{tabular}{|c|c|c|c|c|}
\hline $\mathrm{CO}(\%)$ & Composite Carbide & Hardness (HV) & Toughness(Mpa) & Layer Specifications \\
\hline 11 & 12 & 1420 & 6,9 & $\mathrm{TiN}+\mathrm{Ti}(\mathrm{C}, \mathrm{N})+\mathrm{Al} \mathrm{O}_{3}$ \\
\hline
\end{tabular}

Table 2: Chemical Composition of workpiece Materials (\%)

\begin{tabular}{|c|c|c|c|c|c|c|c|}
\hline $\mathrm{C}$ & $\mathrm{Si}$ & $\mathrm{Mn}$ & $P$ & $\mathrm{~S}$ & $\mathrm{Cr}$ & Mo & $\mathrm{Ni}$ \\
\hline $0,30-0,38$ & $0,15-0,40$ & $0,40-0,70$ & $\leq 0,035$ & $\leq 0,035$ & $1,40-1,70$ & $0,15-0,30$ & $1,40-1,70$ \\
\hline
\end{tabular}

Table 3: Mechanical Properties of workpiece

\begin{tabular}{|c|c|c|c|c|c|c|}
\hline Yield Strength $\left(\mathrm{N} / \mathrm{mm}^{2}\right)$ & Tensile Strength $\left(\mathrm{N} / \mathrm{mm}^{2}\right)$ & Elongation $(\%)$ & Reduction $(\%)$ & Impact Strength $(\mathrm{Joule})$ & Hardness HV \\
\hline 785 & $980-1180$ & 11 & 50 & 48 \\
\hline
\end{tabular}

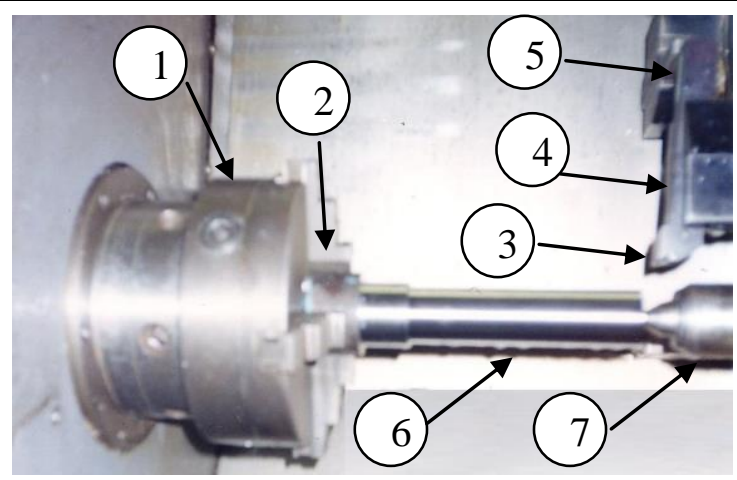

Fig 1: Workpiece installed on $\mathrm{CNC}$ lathe machine
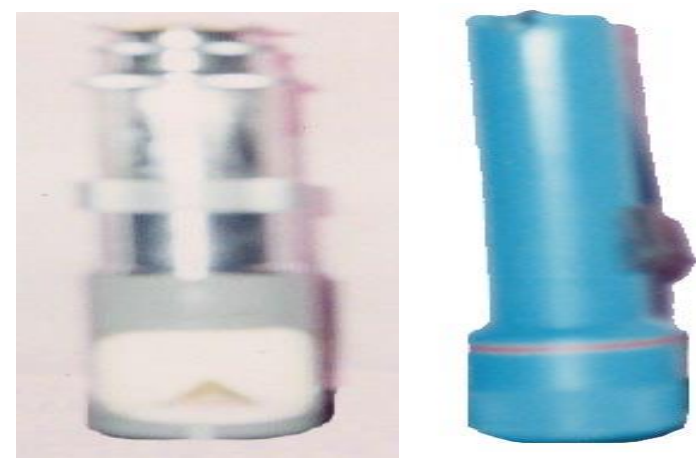

Fig 2: Optical Microscope and Flashlight

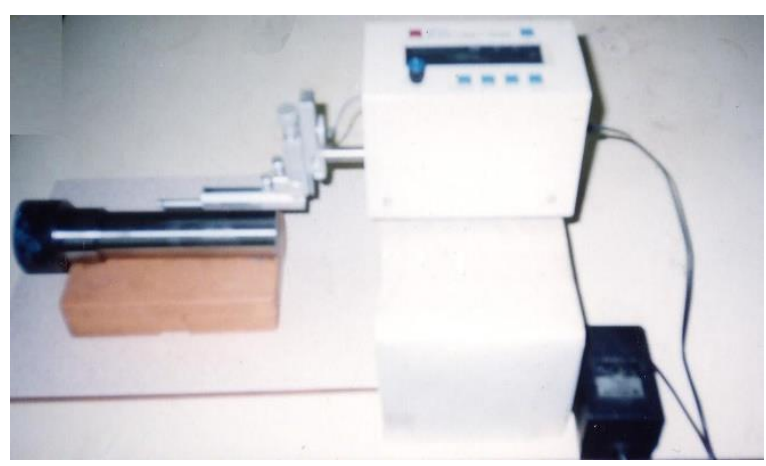

Fig 3: Surface Test

Turning of TEW 6582 alloy steel in the form of a cylindrical rod (length $=200 \mathrm{~mm}$ and $50 \mathrm{~mm}$ diameter) was performed using a CNC machine against standard L9 (3) 4 arrays. Based on these standards can be tested which is given variation of VB wear, cutting condition variation and different tool geometry (table 5). The machining results of the lathe have 9 different cutting forms when performed on wet machining also dry machining. With 3 variations of VB wear, ie $0.1 \mathrm{~mm}, 0.3 \mathrm{~mm}$ and $0.6 \mathrm{~mm}$ of 9 cutting forms, one of the most optimum cutting forms was obtained so that 3 optimum cutting forms were obtained for each wet and dry machine. Thus can be compared wet and dry machining results.
Measurement of surface roughness of machining result used surface test equipment.

The standard equations for surface roughness are

$R_{a}=\frac{f^{2}}{32 r_{c}}$

(Vernon, 2003)

\section{Statistical Equations}

$\mathrm{H}_{0}$ : There is no $R a_{\text {avg }}$ change between dry and wet machining 
$\mathrm{H}_{1}$ : There is $R a_{\text {avg }}$ difference between dry and wet machining

$$
\begin{aligned}
& S_{d 1}=\sqrt{\frac{\sum\left(X_{1}-\bar{X}_{1}\right)^{2}}{n-1}} \\
& S_{d 2}=\sqrt{\frac{\sum\left(X_{2}-\bar{X}_{2}\right)^{2}}{n-1}} \\
& S_{P}^{2}=\frac{\left(n_{1}-1\right) \cdot S^{2}{ }_{11}+\left(n_{2}-1\right) \cdot S^{2} d 2}{n_{1}+n_{2}-2} \\
& Z=\frac{\bar{X}_{1}-\bar{X}_{2}}{S_{P} \sqrt{\frac{1}{n_{1}}+\frac{1}{n_{2}}}}
\end{aligned}
$$

Table 4: Standar Array $\mathrm{L}_{9}\left(3^{4}\right)$

\begin{tabular}{|c|c|c|c|c|}
\hline No & \multicolumn{5}{|c|}{ Column number/Factor } \\
\hline Trial & 1 & 2 & 3 & 4 \\
\hline 1 & 1 & 1 & 1 & 1 \\
\hline 2 & 1 & 2 & 2 & 2 \\
\hline 3 & 1 & 3 & 3 & 3 \\
\hline 4 & 2 & 1 & 2 & 3 \\
\hline 5 & 2 & 2 & 3 & 1 \\
\hline 6 & 2 & 3 & 1 & 2 \\
\hline 7 & 3 & 1 & 3 & 2 \\
\hline 8 & 3 & 2 & 1 & 3 \\
\hline 9 & 3 & 3 & 2 & 1 \\
\hline
\end{tabular}

Table 5: Testing plan for variations $\mathrm{VB}=0,1 \mathrm{~mm} ; 0,3 \mathrm{~mm}$ and $\mathrm{VB}=0,6$ mm with dry dan wet machining

\begin{tabular}{|l|c|c|c|c|}
\hline & \multicolumn{4}{|c|}{ Factor } \\
\hline Exp number & $\begin{array}{c}\boldsymbol{V} \\
\mathrm{m} / \mathrm{min}\end{array}$ & $\begin{array}{c}\mathbf{a} \\
\mathrm{mm}\end{array}$ & $\mathrm{F} \mathrm{mm/r}$ & $\begin{array}{c}\mathrm{Gp} \\
\left(\begin{array}{c}{ }^{\circ} \\
)\end{array}\right.\end{array}$ \\
\hline HPB1; HPK1 & 200 & 1,0 & 0,15 & 6 \\
\hline HPB2; HPK2 & 200 & 1,5 & 0,2 & 12 \\
\hline HPB3; HPK3 & 200 & 2,0 & 0,25 & 18 \\
\hline HPB4; HPK4 & 250 & 1,0 & 0,2 & 18 \\
\hline HPB5; HPK5 & 250 & 1,5 & 0,25 & 6 \\
\hline HPB6; HPK6 & 250 & 2,0 & 0,15 & 12 \\
\hline HPB7; HPK7 & 300 & 1,0 & 0,25 & 12 \\
\hline HPB8; HPK8 & 300 & 1,5 & 0,15 & 18 \\
\hline HPB9; HPK9 & 300 & 2,0 & 0,2 & 6 \\
\hline
\end{tabular}

\section{Results Dan Discussion}

The acquisition of wet and dry machining data through a test with surface test measurements can be plotted into the following diagram of bar chart.

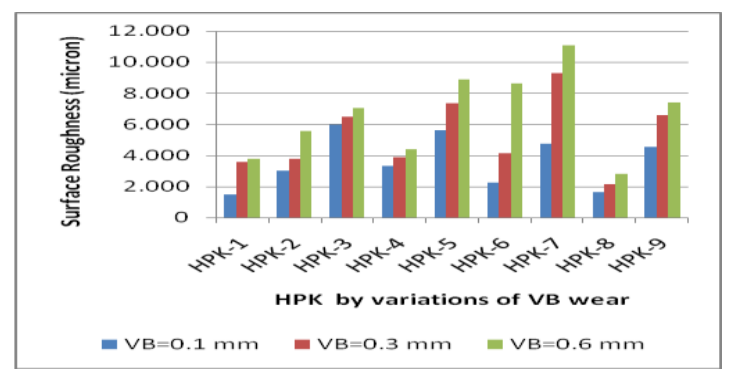

Fig 4: Surface roughness as a function of Variation of VB wear for dry machining

From Figure 4 that Ra changes in VB wear $(0-0.1 \mathrm{~mm})$ with the same cutting depth of $1 \mathrm{~mm}, 1.5 \mathrm{~mm}$ and $2 \mathrm{~mm}$ are the initial wear processes in the machining process wherein $\mathrm{f}$ for $0.15 \mathrm{~mm} / \mathrm{r}$ tends to provide a lower Ravg surface roughness value compared with $0.2 \mathrm{~mm} / \mathrm{r}$ and $0.25 \mathrm{~mm} / \mathrm{r}$ feedings. The change in the rate of Ravg ( $\triangle$ Ravg) from VB (0.1-0.3) $\mathrm{mm}$ averages decreases for the cutting conditions and the tool geometry (Gp) is different. The average occur decrease caused ( $\Delta$ Ravg) $(0-0.1) \mathrm{mm}$ tends to be greater. While the rate of change of Ravg from VB $(0,3-0,6) \mathrm{mm}$ also the relative average decrease because $\Delta$ Ravg wear VB $(0,1-$ $0,3) \mathrm{mm}$ bigger than at VB wear $(0,3-0,6) \mathrm{mm}$. Figure 5 rod shape diagram of wet machining results. The clarification of figure 4 is identical to figure 5, except that the Ravg surface roughness values are different in which the Ravg value in dry machining is slightly lower (not significant). However, the cutting time and length of cutting path is shorter than wet machining. As shown in figure 6 that the greater VB tool wear will tend to produce a poorly machined surface because the Ravg value increases. The comparison of both the above machining results shows that the dry machining has a better machining surface. For the 3 optimum cutting forms shown in Figure 7 that the Ravg value on the surface of dry machining result tends to be slightly smaller than that of wet machining due to the selection of tool as cutting tool with the work piece used may be suitable in determining the cutting parameter when machining process takes place. High cutting speed gives dominant influence and relatively low feeding can obviously reduce cutting force and accelerate tool wear.

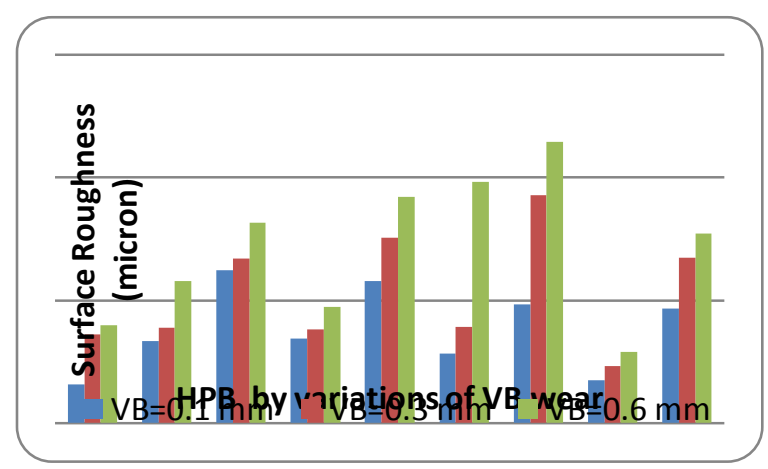

Fig 5: Surface roughness as a function of Variation of VB wear for wet machining

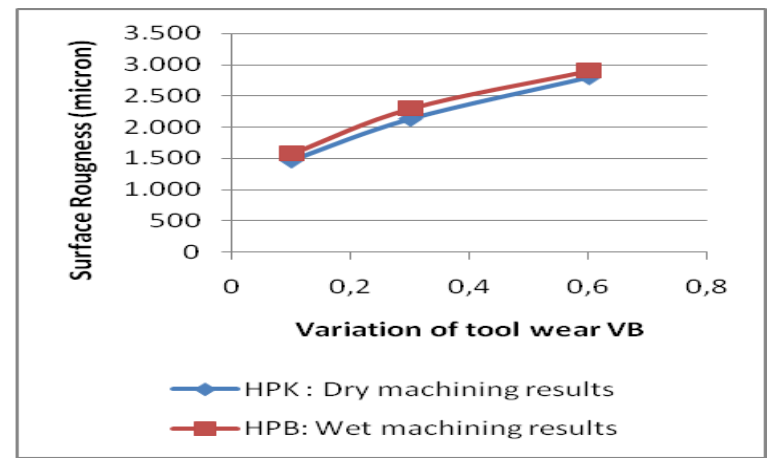

Fig 6: Surface roughness as a function of Variation of tool wear for optimum cutting on dry and wet machining

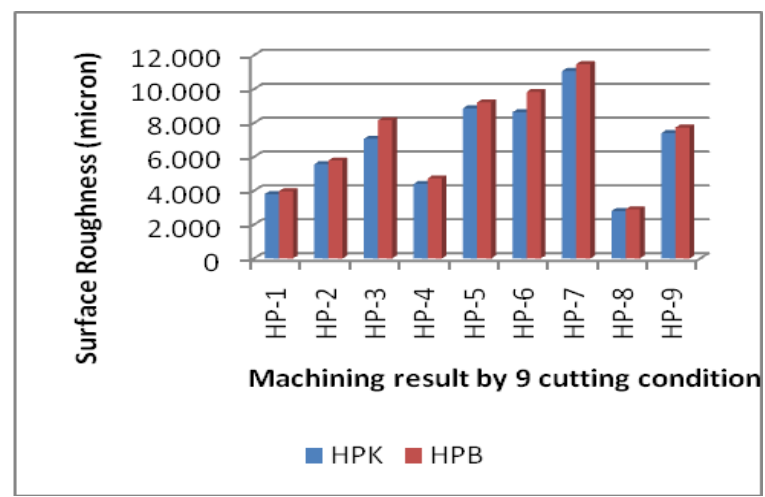

Fig 7: Relation of surface roughness with 9 cutting conditions at dry and wet machining

The curve obtained in figure 6 represents 3 optimum cutting conditions with variation of tool wear using $\mathrm{VB}=0.1 \mathrm{~mm}, 0.3 \mathrm{~mm}$ and $0.6 \mathrm{~mm}$. This comparison shows an insignificant Ravg value in which HPK-1.0.1 $=1.467 \mu \mathrm{m}$ and HPB-1.0.1 $=1.581 \mu \mathrm{m}$ is the initial wear. HPK-8.0.3 $=2,133 \mu \mathrm{m}$ and HPB-8,0.3 $=2,304 \mu \mathrm{m}$ is known as the average wear, in this condition the Ravg value increased due to the cutting tool wear increasing. For HPK-8.0.6 = $2.8 \mu \mathrm{m}$ and HPB-8.0.6 $=2.906 \mu \mathrm{m}$ is said to be the dramatic wear where the Ravg value increases due to the cutting tool undergoes 
increasing wear, its mean the worn-out tool is followed by the increased Ravg value but the Ravg value is obtained meet the desired criteria.

Significant or not between dry and wet machining can be done statistically.

Statistics of Dry and Wet Machining for Roughness of Ravg surface.

$\mathrm{H}_{0}$ : There is no $R a_{\text {avg }}$ change between dry and wet machining

$\mathrm{H}_{1}$ : There is $R a_{\text {avg }}$ difference between dry and wet machining In figure 7 dry and wet machining data are obtained:

$\bar{X}_{1}=\frac{1.467+2.133+2.800}{3}=\frac{6.4}{3}$

$\bar{X}_{1}=2.133$

$\bar{X}_{2}=\frac{1.581+2.304+2.906}{3}=\frac{6.791}{3}$

$\bar{X}_{2}=2.263$

$S_{d 2}=\sqrt{\frac{\sum\left(X_{2}-\bar{X}_{2}\right)^{2}}{n-1}} S_{d 1}=\sqrt{\frac{\sum\left(X_{1}-\bar{X}_{1}\right)^{2}}{n-1}}$

$S_{d 1} \quad$ is obtained

$=\sqrt{\frac{(1.467-2.133)^{2}-(2.133-2.133)^{2}-(2.800-2.133)^{2}}{3-1}}$

$S_{d 1}=\sqrt{\frac{(-0.666)^{2}+(0)^{2}+(0.667)^{2}}{2}}$ then

$S_{d 1}=\sqrt{\frac{(0.4435)+(0)+(0.4448)}{2}}$

$=\sqrt{0.44415}=0.6664$

and then $S_{d 2}$ is

$=\sqrt{\frac{(1.581-2.263)^{2}-(2.304-2.263)^{2}-(2.906-2.263)^{2}}{3-1}}$

$S_{d 2}=\sqrt{\frac{(-0.682)^{2}+(0.041)^{2}+(0.643)^{2}}{2}}$

$S_{d 2}=\sqrt{\frac{(0.465)+(0.002)+(0.413)}{2}}$

$S_{d 2}=\sqrt{\frac{0.88}{2}}$

$S_{d 2}=\sqrt{0.44}$

$=0.6633$

$S^{2}{ }_{p}=\frac{2(0.6664)^{2}+2(0.6633)^{2}}{4}$

$S_{p}^{2}=\frac{(0.8881)^{2}+(0.8799)^{2}}{4}$

$S_{P}=\sqrt{0.442}=0.6648$

\section{Test Statistics:}

$Z=\frac{\bar{X}_{1}-\bar{X}_{2}}{S_{P} \sqrt{\frac{1}{n_{1}}+\frac{1}{n_{2}}}}$

$Z=\frac{2.133-2.263}{0.6648 \sqrt{\frac{2}{3}}}=\frac{-0.13}{0.6648 .0 .8164}$

$Z=-0.239$

$\alpha=0,05 ; Z_{\frac{\alpha}{2}}=Z_{0,025}=1,96$

Which is the value of 1.96 obtained by table.

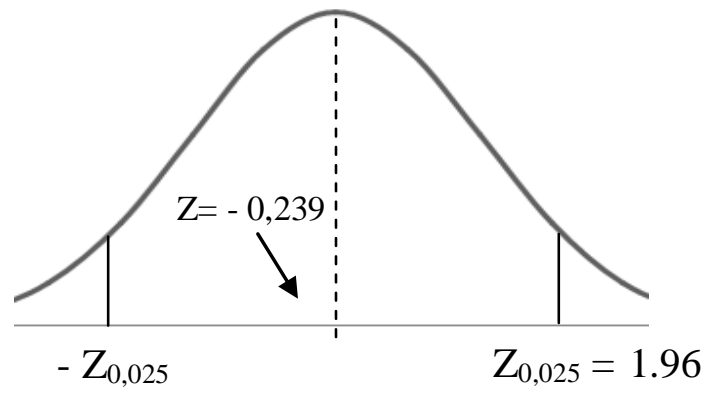

$Z<-Z_{0,025}$

Then $\mathrm{H}_{0}$ is accepted where there is no significant difference between wet machining and dry machining.

\section{Conclusion}

From the results and discussions that have been described above can be taken some conclusions as follows:

1. From the study for the surface roughness value of TEW 6582 alloy steel to the surface of machining results that dry machining is slightly better than wet machining by comparing the machining results in the form of 9 cutting conditions in figure 4 and 5.

2. By 9 cutting conditions of each wear $\mathrm{VB}=0.1 ; 0.3$ and 0.6 $\mathrm{mm}$ obtained Ravg roughness values tend to be larger with VB $=0.6 \mathrm{~mm}$ compared to wear $\mathrm{VB}=0.1 \mathrm{~mm}$ and $0.3 \mathrm{~mm}$ because the tool is worn out but the Ravg roughness can still to meet the criteria.

3. In figure 7 for HPK-8.0.6 and HPB-8.0.6 each have a roughness value Ravg $=2.8 \mu \mathrm{m}$ and $2.906 \mu \mathrm{m}$ smaller than other cutting conditions because it is influenced by high cutting speed $\mathrm{V}$ and low feeding. Thus if HPK-8.0.6 and HPB8.0.6 are compared then the most optimum cutting conditions is at HPK-8.0.6

4. Ravg surface roughness value in dry machining and wet machining is not significant when compared or statistically analyzed. Ravg surface roughness values will be larger followed by increased tool wear which can be seen in figure 6 .

5. To analyze the result data of dry machining and wet machining with test statistic obtained $Z=-0,239$. According to normal distribution curve of left boundary $Z<-Z_{0,025}$, $Z$ value is in acceptable area where there is no significant difference between dry and wet machining in other words dry machining provides an opportunity to be realized in the metal cutting industry.

\section{References}

[1] KalpakjianS, Manufacturing Engineering and Technology. 1995.

[2] A. Hasibuan et al., "Performance analysis of Supply Chain Management with Supply Chain Operation reference model," vol. 1007, pp. 1-8, 2018.

[3] V. Aaron, Factors affecting surface roughness in finish hard turning. 2003.

[4] LiewWYH, Yuan, and N. BKA, Evaluation of Machining of Performance of STAVAX with PCBN Tools. 2004.

[5] W. K. Carter and M. F. Usry, Cost Accounting, 13th ed. Jakarta: Salemba Empat, 2002.

[6] H. M, Cost and Process information Modeling for Dry Machining. 2004.

[7] MTA-SME, The Future of Machining Technology and Porcess Machining Technology Association of The Society Manufacturing Engineering. Machining Technology Trens, 2011.

[8] C. Haroen, G. A, and G. JH, The Influences of tool wear and Tool Life on Surface Integrity During Turning Tool Steel Using Uncoated Carbide. 2000.

[9] A. Hasibuan, Metodologi Penelitian. 2013.

[10] R. M. S. Rodrio P.Zellmann, Fernanda Fontanive, "Wear mechanisms during dry and wet turning of inconel 718 with ceramics tools" Int J Adv Manuf Technology. Verlag London: Springer, 2017.

[11] R. KP and S. VG, “'Dry Machining Of Superalloys', Difficul- ties and Remedies," IJSR, 2012.

[12] B. H, Research \& Technology Transfer Workgroup Dry Machining. 2004.

Test criteria : reject $\mathrm{H}_{0}$ if $Z>Z_{0,025}$ or 